\title{
Clinical and neuropsychological correlation in patients with rolandic epilepsy
}

\author{
Correlação entre achados clínicos e neuropsicológicos em pacientes com epilepsia rolândica \\ Livia L. Medeiros Capelatto, Ecila Paula M. Oliveira, Marina L. Neri, Catarina A. Guimarães, Maria Augusta \\ Montenegro, Marilisa M. Guerreiro
}

\begin{abstract}
Objectives: To evaluate the presence of neurological soft signs (NSS) and to correlate them with the Wechsler Intelligence Scale for Children (WISC III) in patients with rolandic epilepsy (RE). Methods: Forty children and adolescents aged between 9 and 15 years were studied. They were divided into two groups: G1 - patients with RE $(n=20)$ - and $G 2$ - healthy controls without epilepsy $(n=20)$. They were assessed with the Quick Neurological Screening Test (QNST II) - clinical trial to search for NSS -, and the WISC III - neuropsychological test. Results: No statistical difference between groups was found in WISC III and QNST II. However, children with poorer motor skills had worse performance in the QNST II and also in the execution intelligence quotient $-I Q(p=0.001)$ and in total $I Q(p=0.004)$, thus showing a positive correlation between them. Conclusions: The QNST II is a good screening tool for the neurologist to detect abnormalities in fine motor skills.
\end{abstract}

Key words: epilepsy, rolandic epilepsy, neurological soft signs.

\section{RESUMO}

Objetivos: Avaliar a presença de sinais neurológicos menores (SNM) e correlacioná-los com o Escala de Inteligência de Wechsler para Crianças (WISC III) em pacientes com epilepsia rolândica (ER). Métodos: Foram estudados 40 crianças ou adolescentes entre 9 e 15 anos, divididos em dois grupos: $\mathrm{G} 1$ - pacientes com ER ( $n=20)$; $\mathrm{G} 2$ - controles saudáveis sem epilepsia $(n=20)$. Foram avaliados por meio do QNST II - teste clínico que pesquisa SNM - e do WISC III - teste neuropsicológico. Resultados: Não foi encontrada nenhuma diferença estatística entre os grupos no WISC III e QNST II. Entretanto, crianças com habilidades motoras pobres tiveram pior desempenho no QNST II, assim como no quociente de inteligência (QI) de execução $(p=0,001)$ e no QI total ( $p=0,004)$, mostrando, portanto, correlação positiva entre os dois instrumentos. Conclusões: O QNST II é uma boa ferramenta de rastreamento para o neurologista detectar anormalidades nas habilidades motoras finas.

Palavras-Chave: epilepsia, epilepsia rolândica, sinais neurológicos menores.

Focal epilepsy of childhood with centrotemporal spikes, or rolandic epilepsy (RE), is the most common form of childhood epilepsy, occurring in children between three and 13 years-old with normal psychomotor development, according to the International Classification of Epilepsies and Epileptic Syndromes ${ }^{1}$. Patients may present with simple or complex partial seizures, most commonly involving the face, with or without involvement of the ipsilateral upper limb and, more rarely, evolving to generalized seizure.

$\mathrm{RE}$ is usually considered 'benign' because there is seizure remission during adolescence without future major impairments $^{2,3}$. However, subtle neuropsychological deficits, behavioral disturbances, and difficulties in school performance, particularly in relation to reading and writing skills, may occur. It is still not clear if these abnormalities can be observed only in the active phase of epilepsy ${ }^{4,5}$, that is, if the transitory cognitive impairments occur exclusively during subclinical epileptiform discharges ${ }^{6-8}$. On the other hand, evidence suggest that such abnormalities are observed both before the active phase and during the postactive phase of epilepsy9.

The presence of neurological soft signs in RE patients has not been addressed. Our study aimed at investigating and correlating clinical features, through the search of neurological soft signs, with the neuropsychological deficits in patients with RE.

\section{METHODS}

Forty children and adolescents aged between 9 and 15 years old were studied. RE patients were selected from the outpatient Clinic of Childhood Epilepsy of our university hospital, and the Control Group consisted of healthy children and adolescents from the

Department of Neurology, Faculdade de Ciências Médicas (FCM), Universidade Estadual de Campinas (Unicamp), Campinas SP, Brazil.

Correspondence: Marilisa M. Guerreiro; Department of Neurology, FCM, Unicamp; Rua Tessália Vieira de Camargo 126; $13083-887$ Campinas SP - Brasil;

E-mail:mmg@fcm.unicamp.br

Conflict of interest: There is no conflict of interest to declare.

Received 25 April 2012; Received in final form 04 May 2012; Accepted 11 May 2012 
Municipal School of Basic Education (EMEF) Elvira Muraro, in Campinas, in the State of São Paulo, Brazil.

Children and adolescents were divided into two groups: G1 $(n=20)$ consisted of patients with RE according to the International League Against Epilepsy (ILAE) criteria ${ }^{1}$, and G2 ( $n=20)$, the Control Group, consisted of healthy children without epilepsy. Most G1 patients (85\%) had their epilepsy controlled (17 out of 20 patients).

All children and adolescents were assessed with the Quick Neurological Screening Test (QNST II), which is a clinical trial to search for neurological soft signs, and the Wechsler Intelligence Scale for Children (WISC III). The neuropsychological tests were applied by a qualified professional.

Data analysis was performed using the Statistical Package for Social Sciences (SPSS), version 17.0, and the MannWhitney's test to verify the difference between the two groups.

\section{RESULTS}

Table 1 compares the QNST II data, considering its subdivisions and the chronological age of both groups. There was no statistically significant difference between them.

Table 2 shows the comparison between the final scores of the QNST II and neuropsychological assessments (WISC III) in patients who underwent both tests. There was no statistical

Table 1. Correlation between the two groups regarding age and subdivisions of the Quick Neurological Screening Test II.

\begin{tabular}{ccccc} 
Variable & Group & $\begin{array}{c}\text { Standard } \\
\text { deviation }\end{array}$ & Average & p-value \\
\hline \multirow{2}{*}{ Age } & G1 & 2.63 & 11.00 & 0.764 \\
& G2 & 1.78 & 11.00 & \\
NL & G1 & 2.92 & 11.50 & 0.869 \\
& G2 & 2.08 & 12.00 & \\
MD & G1 & 1.97 & 3.50 & 0.869 \\
& G2 & 1.78 & 3.00 & \\
SD & G1 & 1.57 & 0.50 & 0.195 \\
\hline
\end{tabular}

NL: normal; MD: moderate deviation; SD: severe deviation.

Table 2. Correlation between the Wechsler Intelligence Scale for Children III and the Quick Neurological Screening Test II.

\begin{tabular}{ccccc} 
Group & Test & WISC II* & QNST I** & p-value \\
\hline G1 & Verbal IQ & 112.93 & 18.10 & \\
G2 & & 105.20 & 16.85 & 0.077 \\
G1 & & 114.86 & 18.10 & \\
G2 & Execution IQ & 97.07 & 16.85 & 0.001 \\
G1 & & 114.29 & 18.10 & \\
G2 & Total IQ & 103.43 & 16.85 & 0.004 \\
\hline
\end{tabular}

*Average values were analyzed. IQ: intelligence quotient; QNST ॥: Quick Neurological Screening Test II; WISC III:Wechsler Intelligence Scale for Children III. difference between the groups. However, there was agreement between the QNST II (when searching for neurological soft signs) and the WISC III (assessment of intelligence quotient - IQ) with statistically significant results between total IQ and QNST II ( $\mathrm{p}=0.004)$ and execution IQ and QNST II $(\mathrm{p}=0.001)$. Therefore, higher IQ correlated with better performance in the QNST II.

\section{DISCUSSION}

Epilepsy is often associated with cognitive impairment, particularly in children. The relationship between epilepsy and cognitive functions is multifactorial and involves age of seizure onset, seizure frequency, presence or absence of structural damage, use of antiepileptic drugs (mono - or polytherapy), and so on. RE is one of the most common forms of childhood epilepsy, accounting for 14 to $17 \%$ of children with epilepsy under 16 years of age $\mathrm{e}^{2,10}$. The clinical presentation is relatively homogeneous and there is no structural damage of the brain, which makes RE a good model to investigate neuropsychological, behavioral, and educational comorbidities. Neurological soft signs have not been investigated yet. To our knowledge, this is the first study to address this issue.

Although neuropsychological and behavioral changes in idiopathic benign childhood epilepsy have already elicited interest and subtle impairments, a wide variety of higher cortical functions (memory, visuomotor skills and visuospatial, spatial perception, memory spatial, coordination, different areas of language, content discrimination, and auditory-verbal dyspraxia) have been documented ${ }^{11,12}$. Even after the active phase of seizures ${ }^{9}$, little is known about neurological soft signs in such group of patients.

In our results, the QNST II showed no statistically significant difference between controls and children with RE. However, some considerations can be given. Firstly, neurological soft signs might be present in the active phase of epilepsy, and most of our patients (85\%) were out of the active phase of seizures ${ }^{4,5,13,14}$. Secondly, data correlation from the WISC III and QNST II, particularly the execution IQ with QNST II, should be emphasized. The QNST II is designed to detect soft neurological signs related to motor activity, coordination, and balance. Motor skills are necessary to carry out the tasks of both QNST II and execution IQ. Our findings showed that children with poorer motor skills have worse performance in QNST II as well as in execution IQ, thus showing a positive correlation between the two tests.

We have gotten to the conclusion that the QNST II is a good screening tool for the neurologist to detect abnormalities in fine motor skills, since there was correlation of the findings with the WISC III. 


\section{References}

1. Berg AT, Berkovic SF, Brodie, MJ, et al. Revised terminology and concepts for organization of seizures and epilepsies: Report of the ILAE Commission on Classification and Terminology, 2005-2009. Epilepsia 2010;51:676-685.

2. Lerman P, Kivity S. Benign focal epilepsy of childhood. A follow-up study of 100 recovered patients. Arch Neurol 1975;32:261-264.

3. Bouma PA, Bovenkerk AC, Westendorp RG, Brouwer OF. The course of benign partial epilepsy of childhood with centrotemporal spikes: a meta-analysis. Neurology 1997;48:2:430-437.

4. Hommet C, Billard C, Motte J, et al. Cognitive function in adolescents and young adults in complete remission from benign childhood epilepsy with centro-temporal spikes. Epileptic Disord 2001;3:207-216.

5. D’Alessandro P, Piccirilli M, Tiacci C, et al. Neuropsychological features of benign partial epilepsy in children. Ital J Neurol Sci 1990;11:265-269.

6. Binnie CD, Marston D. Cognitive correlates of interictal discharges. Epilepsia 1992;33(Suppl 6):S11-S17.

7. Fonseca LC, Tedrus GM, Pacheco EM. Epileptiform EEG discharges in benign childhood epilepsy with centrotemporal spikes: reactivity and transitory cognitive impairment. Epilepsy Behav 2007;11:65-70.
8. Baglietto MG, Battaglia FM, Nobili N, et al. Neuropsychological disorders related to interictal epileptic discharges during sleep in benign epilepsy of childhood with centrotemporal or rolandic spikes. Dev Med Child Neurol 2001;43:407-412.

9. Hermann BP, Jones J, Sheth R, Seidenberg M. Cognitive and magnetic resonance volumetric abnormalities in new-onset pediatric epilepsy. Semin Pediatri Neurol 2007:14:173-180.

10. Panayiotopoulos CP. Benign childhood partial epilepsies: benign childhood seizures susceptibility syndromes. J Neurol Neurosurg Psychiatry 1993;56:2-5.

11. Lindgren A, Kihlgren M, Melin L, Croona C. Development of cognitive functions in children with rolandic epilepsy. Epilepsy Behav 2004;5:903-910.

12. Weglage J, Demsky A, Pietsh M, Kurlemann G. Neuropsychological, intellectual, and behavioral findings in patients with centrotemporal spikes with and without seizure. Dev Med Child Neurol 1997;39:645-651.

13. Deonna T. Rolandic epilepsy: neuropsychology of the active epilepsy phase. Epileptic Disord 2000;2(Suppl 1):S59-S61.

14. Deonna T, Zesiger P, Davidoff $V$, et al. Benign partial epilepsy of childhood: a longitudinal neuropsychological and EEG study of cognitive function. Dev Med Child Neurol 2000;42:595-603. 